\title{
CONVERGÊNCIA DAS NORMAS BRASILEIRAS APLICADAS AO SETOR PÚBLICO: UM ESTUDO EXPLORATÓRIO NO MUNICÍPIO DE UBERLÂNDIA - MG
}

\author{
CONVERGENCE OF BRAZILIAN STANDARDS APPLIED TO PUBLIC SECTOR: \\ AN EXPLORATORY STUDY IN UBERLÂNDIA - MG
}

\author{
Kamila Batista Melo \\ kamilabmelo@gmail.com \\ Universidade Federal de Uberlândia
}

\author{
Marina Freitas Prieto \\ marina_mfp@yahoo.com.br \\ Universidade Federal de Uberlândia
}

\author{
Maria Elisabeth Moreira Carvalho Andrade \\ melizabeth@facic.ufu.br \\ Universidade Federal de Uberlândia
}

\begin{abstract}
RESUMO
Este artigo tem por objetivo analisar a percepção dos servidores públicos quanto à convergência Normas Brasileiras Aplicadas ao Setor Público, no município de Uberlândia. Para atingir este objetivo foi realizada uma pesquisa exploratória sendo realizada por meio de uma pesquisa de campo, com aplicação de questionário na escala likert, em órgãos públicos: federal, estadual e municipal. O tratamento de dados foi realizado de três formas: análise do Ranking Médio (RM), para as questões específicas; estatística descritiva para as questões que tratam do perfil dos respondentes e a técnica multivariada HOMALS. Conclui-se que os servidores estão cientes da importância da convergência e possuem um nível básico de conhecimento sobre o tema, entretanto, não está havendo empenho pelos órgãos públicos do município de Uberlândia para a capacitação dos mesmos para a efetiva implantação das normas internacionais.
\end{abstract}

\begin{abstract}
This article aims to analyze the perception of public servants as the convergence Brazilian Standards Applied to the Public Sector, in Uberlândia. Federal, state and municipal: To achieve this goal an exploratory research being conducted through a field survey with a questionnaire in Likert scale in government offices was held. Data processing was carried out in three ways: analysis of Middle Ranking (MR), for specific issues; Descriptive statistics for questions dealing with the profile of the respondents and the multivariate technique HOMALS. We conclude that the servers are aware of the importance of convergence and have a basic level of knowledge on the subject, however, is not with great effort by public agencies in the municipality of Uberlândia for training the same for the effective implementation of international standards.
\end{abstract}

Artigo recebido em: 10.04.2014; Aceito em: 07.07.2014

\section{INTRODUÇÃO}

A contabilidade brasileira nos últimos anos está em evidência devido à convergência às normas internacionais. Este processo está sendo vivenciado pelos setores privado e público desde 2008, sendo que o setor privado concluiu esse processo ao final de 2010. Quanto ao setor público a 
convergência está acontecendo paulatinamente. A adoção das normas contábeis aplicadas ao setor público já está sendo praticada parcialmente pela União e alguns Estados. De acordo com as Portarias MF $n^{\circ}$ 821/11 e 231/12, todos os entes da federação têm até o final de 2014 para adoção integral.

A Contabilidade Pública sempre esteve voltada para atender ao aspecto técnico e legal, esquecendo da importância de fornecer informações para os usuários, bem como um instrumento de planejamento e controle para os gestores possibilitando alcançar a eficiência e eficácia na aplicação dos recursos públicos (ROSA, 2011). Muito se espera da convergência às normas contábeis aplicadas ao setor público, mas existem inúmeros obstáculos a serem vencidos, peculiares ao setor. Diversos fatores institucionais podem influenciar positivamente ou não a adoção das normas em sua plenitude. É uma mudança de paradigma que precisa ser incorporado na administração pública.

A contabilidade deve possibilitar maior accountability possível, por meio das demonstrações contábeis, auxiliando também na tomada de decisão. As demonstrações financeiras fornecem evidências para aumentar a transparência nos governos, bem como accountability (PÉREZ, LÓPEZ-HERNÁNDEZ, 2009).

Assim, nos governos democráticos e modernos, a transparência e accountability são condições essenciais na condução da boa governança tanto para o setor privado como para o

setor público (SANTANA JUNIOR, 2008). Informações financeiras de baixa qualidade prejudica o setor público na tomada de decisão, principalmente quanto à definição de políticas públicas e ainda favorece a corrupção e malversação dos recursos públicos.

Os gestores públicos precisam se conscientizar da importância da modernização da contabilidade pública, sendo premente a diminuição da assimetria informacional entre o Estado e sociedade. E a partir daí capacitar os servidores para a efetiva convergência, pois, nenhuma reforma administrativa é possível sem a conscientização e apoio dos atores que conduzem a máquina pública.

Revoredo (2008) alerta que grande parte do funcionalismo público possui características conservadoras, podendo ser um empecilho para qualquer tipo de proposta administrativa.

Mais uma vez destaca-se a importância da qualificação dos servidores. É preciso promover palestras elucidativas e educativas para quebrar esse paradigma.

Diante deste contexto, a questão investigativa é: Qual é a percepção dos servidores públicos do município de Uberlândia quanto a convergência às normas internacionais de contabilidade aplicadas ao setor público? Assim, aventa-se a hipótese de que, apesar da convergência ter iniciado em 2008, os servidores públicos ainda estão desatualizados para a efetiva convergência contábil aplicada no setor público. Em outras palavras, para uma convergência bem sucedida é necessário treinamento e atualização dos servidores públicos.

Este artigo tem por objetivo geral analisar a percepção dos servidores públicos quanto à convergência Normas Brasileiras Aplicadas ao Setor Público, no município de Uberlândia. O presente estudo, além desta introdução, conta com mais quatro seções. A próxima seção traz o referencial teórico, seguida dos aspectos metodológicos. A quarta seção apresenta os resultados. E por último são realizadas as considerações finais com sugestões de pesquisas futuras.

\section{REFERENCIAL TEÓRICO}

Para melhor compreensão esta seção está dividida em três partes:

2.1 Breve histórico da convergência 
Nas últimas décadas a Administração Pública vem se modernizando, transformando a burocrática e ineficaz Administração Pública em gerencial, orientada pela eficiência e eficácia na prestação dos serviços públicos (BRESSER-PEREIRA, 1996; BRESSER-PEREIRA e SPINK,1998; MATIAS-PEREIRA, 2008). Esse processo foi denominado como New Public Management (NPM), sendo marcado pela restruturação das agências governamentais, ou seja, a descentralização dos serviços públicos e maior ênfase na mensuração dos resultados e accountability (JÄRVINEN, 2009).

No Brasil não foi diferente do resto do mundo, a administração Pública também teve que ser reformulada. Em 1995 foi aprovado o Plano Diretor da Reforma do Estado, elaborado pelo Ministério da Administração Federal e da Reforma do Estado - MARE. Um dos objetivos do plano foi melhorar a governança, transformando a Administração Pública burocrática, rígida e ineficiente, voltada para si própria e para o controle interno, em uma Administração Pública gerencial, flexível e eficiente, voltada para o atendimento do cidadão.

E a modernização da contabilidade pública faz parte dessa reforma. Em 2008, foi editada a Portaria $\mathrm{n}^{\circ}$ MF 184/08 que estabeleceu critérios para a convergência da contabilidade pública brasileira às IPSAS (International Public Sector Accounting Standards), emitidas pelo IFAC (International Federation of Accountants).

O IFAC é uma organização global composta por 167 membros de 127 países e tem por missão contribuir para o desenvolvimento, adoção e implementação de normas e regulamentos de alta qualidade (IFAC, 2012). Mas o IFAC não possui poder de enforcement, cada país tem que realizar essa função. No Brasil, quem realiza a regulação contábil para o setor público é o Ministério da Fazenda através da Secretaria do Tesouro Nacional (STN) em conjunto com o Conselho Federal de Contabilidade (CFC).

Espera-se com a adoção das normas internacionais aplicada ao setor público uma gestão pública mais transparente e eficiente. As IPSAS têm como referência as normas emitidas pelo IASB (International Accounting Standards Board), ou seja, normas voltadas ao setor privado. Existem correntes favoráveis e desfavoráveis quanto a adoção de normas públicas que possuem referência com as do setor privado.

Ribeiro Filho et al (2009, p. 06) acreditam que: “Com a possibilidade de utilização dos conceitos antes utilizados somente pelo setor privado para o setor público na condição essencial de prestação de serviço fica caracterizado importante avanço." Portanto, os autores são favoráveis a adoção de conceitos do setor privado. Morais e Platt Neto (2012, p. 2) citam que:

\footnotetext{
"Apesar de ter a sua origem vinculada ao setor privado, o movimento de convergência contábil estendeu-se ao setor público a partir de uma perspectiva em comum: possibilidade de comparabilidade dos resultados alcançados pelos governos e ampliação da qualidade da evidenciação contábil desse setor."
}

Piscitelli, Timbó e Rosa (2006) já discordam dessa visão, os autores citam que: "As demonstrações contábeis referentes ao setor público sejam elas no âmbito Federal, Estadual ou Municipal estão sujeitas a normas estritas e procedimentos específicos, divergindo assim do setor privado."

Em 2008, o Conselho Federal de Contabilidade (CFC) emitiu as primeiras Normas de Contabilidade Aplicadas ao Setor Público, as NBC T 16 que tem como objetivo contribuir para o reconhecimento, a mensuração e a evidenciação de atos e fatos administrativos

fundamentados na Teoria da Contabilidade. Assim, além de cumprir os aspectos legais e formais, a Contabilidade Pública brasileira reflita a essência das transações governamentais e seu impacto no patrimônio (LIMA, SANTANA e GUEDES, 2009).

Darós e Pereira (2009) entendem que "em sentido amplo as novas normas são um instrumento para elevar a eficácia e efetividade das Leis quanto aos seus objetivos de promover o planejamento, a transparência e responsabilidade da gestão físcal’. Já Azevedo (2009, p. 33) cita 
que "as NBCASP trazem profundos impactos não só na escrituração contábil dos fatos contábeis próprios do setor público, mas também trará reflexos comportamentais no cotidiano dos contabilistas".

Várias são as perspectivas com a convergência, entre elas, melhor evidenciação de ativos e passivos, inclusive os contingentes e a implementação dos sistemas de custos (MORAIS e PLATT NETO, 2012).

A Secretaria do Tesouro Nacional - STN cita em nota sobre a aplicabilidade das normas internacionais, que entre os desafios para a implementação das normas estão: (i) falta de mão de obra especializada; (ii) falta de preparação dos profissionais (ou falta de educação continuada); (iii) desenvolvimento de sistemas de informação adequados; (iv) necessidade de interligação entre os vários setores da administração pública (setor de patrimônio, contábil, recursos humanos, jurídico, de arrecadação, etc.); (v) questões culturais (forte influência de uma cultura orçamentária).

Enfim, a convergência às normas internacionais aplicadas ao setor público, no Brasil é uma realidade. Entretanto, o seu sucesso ainda não é certo. Há muito que fazer e dificuldades a serem enfrentadas e se não houver engajamento, principalmente dos gestores públicos, ela pode não ocorrer na prática.

\subsection{Regime de Competência (accrual basis) e Regime de Caixa (cash basis)}

Na contabilidade pública brasileira existe a figura do regime contábil "misto", onde se reconhece a receita por regime de caixa e as despesas pelo regime de competência, devido à interpretação do art. 35 da Lei 4.320/64: "Art. 35. Pertencem ao exercício financeiro: I - as receitas nele arrecadadas; II - as despesas nele legalmente empenhadas."

No regime de Caixa, as despesas e receitas são caracterizadas pelas saídas e entradas de recursos financeiros (dinheiro). Wynne (2007) afirma que o regime de caixa ainda é utilizado por quase todos os setores públicos, em muitos países, entretanto muitos já vêm aderindo ao regime de competência.

No regime de caixa, os recebimentos e os pagamentos são reconhecidos somente quando se recebe ou se paga mediante dinheiro ou equivalentes de caixa. O regime contábil misto tem objetivo de manter o controle orçamentário das entidades públicas. Sendo que o controle patrimonial não estava sendo realizado. Os bens públicos, em sua maioria não são registrados pela contabilidade atualmente. E os poucos que são evidenciados não estão sendo depreciados, por exemplo.

Segundo Lima e Castro (2003):

A Contabilidade Pública independe de qualquer outro fato ou questão de natureza jurídica ou administrativa, reconhece receita apenas no momento em que o recurso é repassado ao agente arrecadador do governo (seja ele pública ou Privada), com exceção dos beneficiários de transferências de recursos intergovernamentais, que registrarão a receita tendo como contrapartida um direito.

Com a adoção das IPSAS passará a ser adotado regime contábil de competência em sua integralidade (full acrrual basis). No regime de Competência, as despesas e as receitas são contabilizadas pela ocorrência de seus fatos geradores, independente das saídas ou entradas de dinheiro.

Segundo o IFAC (2006), traduzido por Pigatto et al (2010, p. 826), afirma que:

Regime de competência é o regime contábil segundo o qual transações e outros eventos são reconhecidos quando ocorrem (não somente quando o caixa ou seus equivalentes são recebidos ou pagos). Portanto, as transações e eventos são registrados contabilmente e reconhecidos nas demonstrações contábeis referentes aos

R. Cont. Ufba, Salvador-Ba, v. 8, n. 2, p. 21 - 35, mai-ago 2014 
respectivos períodos. Os elementos reconhecidos sob o regime de competência são ativos, passivos, patrimônio líquido/ativos líquidos, receitas e despesas.

A Resolução CFC n ${ }^{\circ} 1.128 / 2008$, que aprovou a NBC T 16.1 - Conceituação, Objeto e Campo de Aplicação dispõe que: "A contabilidade pública deve cumprir a sua função social, refletindo o ciclo da administração pública, evidenciando as informações necessárias à tomada de decisões, à prestação de contas e à instrumentalização do controle social”. E uma grande parte dos estudiosos entendem que somente o regime de competência pode gerar informações úteis para tomada de decisão.

Segundo SÖTHE e SCARPIN (2010) afirmam que se "de um lado o regime de caixa facilita os registros contábeis, de outro lado, limita o nível da informação contábil, distorcendo o resultado do exercício e demonstrando, unicamente, o resultado financeiro do período". As informações geradas pelo regime de caixa podem ser úteis para tomada de decisão a curto prazo.

Reis (2006) também é a favor da adoção do regime de competência:

\begin{abstract}
A adoção do regime de competência tende a beneficiar a administração das entidades governamentais, pois possibilita maior controle e evidenciação da situação econômicofinanceira do ente governamental, e ressalta que o regime de caixa tem provocado distorções nas receitas governamentais, em virtude de não possibilitar a visualização integral do seu volume no exercício.
\end{abstract}

Segundo Zarth (2010) o reconhecimento e a mensuração por competência, decorrente da alteração do regime, provoca impactos significativos na estrutura patrimonial e de resultado do governo. Entretanto, há uma corrente que não concorda com a utilização de normas do setor privado serem aplicadas no setor público, tendo em vista que os objetivos são diferentes (ver Ellwood and Newberry, 2007).

É premente um conjunto de normas uniforme e robusta para o setor público com o objetivo de proporcionar estabilidade ao sistema econômico global e aumentar a accountability e eficiência dos governos (ERNEST \& YOUNG, 2010).

E ainda a sociedade nos últimos anos resgatando a cidadania, com interesse em tomar conhecimento de como e onde estão sendo aplicados os impostos pagos por ela. É necessário estabelecer um diálogo mais próximo dos cidadãos, diminuindo a assimetria informacional. $\mathrm{E}$ as demonstrações contábeis podem e devem auxiliar nesse controle (ANDRADE e CARVALHO, 2013).

\title{
2.3 Lei de Responsabilidade Fiscal - LRF
}

Outro grande avanço para o setor público foi a sanção da Lei de Responsabilidade Fiscal (LRF), em 2000, que tem por objetivo equilibrar as contas públicas. A LRF trata da escrituração e consolidação das contas, visando à transparência e ao controle das contas públicas. Como as informações contábeis acerca do patrimônio público têm a finalidade de atender aos interesses dos usuários, e, consequentemente, contribuem para a evidenciação das informações (LIMA, SANTANA e GUEDES, 2009).

Uma das características fundamentais da LRF é o controle que passou a ser exercido com maior facilidade devido à introdução de novos relatórios de acompanhamento da gestão fiscal, que, além da obrigatoriedade de publicação, deverão estar disponibilizados na Internet (KHAIR, 2000).

A LRF possui uma seção específica que trata da transparência na gestão fiscal (artigos 48; 48-A e 49). Entretanto, segundo Platt Neto et al (2007), a transparência pressupõe a publicidade e compreensibilidade das informações. Portanto, se a informação divulgada não for compreensível por seus diversos usuários, não atinge a transparência exigida pela LRF. 
A convergência poderá auxiliar os entes públicos a cumprirem a LRF. A NBCASP irá facilitar o atendimento dos instrumentos de transparência da gestão e de sua forma de acesso e divulgação para a sociedade, exigidos pela LRF (DARÓS e PEREIRA, 2009).

Enfim, "a nova contabilidade pública" pode aumentar a transparência no setor público, principalmente para os usuários externos e para os usuários internos pode gerar relatórios eficientes para a tomada de decisão econômica e traçar políticas públicas eficazes.

\section{ASPECTOS METODOLÓGICOS}

Esta pesquisa está classificada no modelo proposto por Vergara (1998). Quanto aos fins esta pesquisa classifica-se como exploratória e quanto aos meios trata-se de uma pesquisa de campo. Segundo Vergara (1998, p. 45), a pesquisa exploratória é realizada em área na qual há pouco conhecimento acumulado e sistematizado. E a pesquisa de campo é uma investigação empírica realizada no local onde ocorre ou ocorreu um fenômeno ou que dispões de elementos para explicálo.

A pesquisa exploratória pode ser realizada por entrevista, aplicação de questionário, testes e observação participante ou não (VERGARA, 1998).

\subsection{Coleta de dados}

Nesta pesquisa a coleta de dados foi realizada por questionário, composto de duas partes. A primeira contém questões que envolvem o perfil dos respondentes. A segunda parte foi construída com base na escala Likert de cinco pontos. O questionário não possui questões abertas.

Foi realizado o pré-teste no mês de abril de 2012 com objetivo de assegurar a compreensão e abrangência das questões com três pessoas ligadas a órgãos públicos: Prefeitura Municipal de Uberlândia, Universidade Federal de Uberlândia e Ministério Público de Minas Gerais. Após o pré-teste foram realizadas algumas modificações devido a sugestões dos participantes acima. Vale ressaltar que os mesmos não participaram da amostra final. A pesquisa foi realizada em diversos órgãos com sede no município de Uberlândia: Receita Federal, Receita Estadual de Minas Gerais, Prefeitura Municipal, Banco do Brasil, Universidade Federal de Uberlândia e Ministério Público de Minas Gerais.

A pesquisa de campo foi realizada entre os meses de maio e junho de 2012, com a utilização de um questionário. O questionário foi aplicado em órgãos públicos: federal, estadual e municipal, do município de Uberlândia, todos ligados direta ou indiretamente com a contabilidade pública. Ao todo foram respondidos 37 (trinta e sete) questionários.

Considerou-se que os respondentes teriam as condições necessárias, pois, são servidores que trabalham no setor público que de algum modo possuem relação com o tema pesquisado, conforme será exposto na análise dos resultados.

\subsection{Análise dos Dados}

O tratamento de dados foi realizado de três formas: (i) utilizando o cálculo do Ranking Médio (RM), para as questões específicas; (ii) estatística descritiva para as questões que tratam do perfil dos respondentes e (iii) utilizando a técnica multivariada, a análise de homogeneidade de HOMALS (Homogeneity Alternating Least Square).

Os dados das questões em que foram utilizadas a escala Likert serão analisados primeiramente pela demonstração da participação de cada alternativa em relação à questão proposta e a análise do Ranking Médio (RM) obtido a partir da tabulação das notas obtidas e apontar o nível de aceitação das assertivas. 
Sobre este aspecto, quanto mais próximo for o RM do número 1 maior é a possibilidade de concordância total dos respondentes; de outra parte, quanto mais próximo o RM for do número 5, maiores as chances de a maioria dos respondentes discordarem sobre a afirmativa. Essa técnica, segundo Oliveira (2005), serve para analisar a concordância ou discordância quanto às questões respondidas.

Nesse estudo, os valores menores que 3 são considerados como concordantes e, maiores que 3, como discordantes, considerando uma escala de 5 pontos. O valor exatamente

3 seria considerado "indiferente" ou "sem opinião", sendo o "ponto neutro", equivalente aos casos em que os respondentes deixaram em branco.

Quanto à análise estatística, optou-se pela análise de homogeneidade (HOMALS)

porque segundo Fávero et. al. (2009, p.11), "é uma técnica de descrição de dados qualitativos, particularmente bem adaptado ao tratamento de dados de pesquisa, em que questões são relacionadas a múltiplas escolhas".

\section{APRESENTAÇÃO E ANÁLISE DOS RESULTADOS}

\subsection{Perfil dos Respondentes}

A tabela 01 traz os respondentes por gênero, sendo a maioria do sexo masculino. A faixa etária foi bastante diversificada conforme demonstrado na tabela 02. A maioria dos funcionários é efetivo (tabela 03), sendo que $41 \%$ (quarenta e um por cento) possuem entre seis a dez anos de exercício no setor público (tabela 04).

Tabela 01: Respondentes por Gênero

\begin{tabular}{cccc}
\hline & Masculino & Feminino & Total \\
\hline Frequência & 21 & 16 & 37 \\
$\%$ & $57 \%$ & $43 \%$ & $100 \%$ \\
\hline
\end{tabular}

Tabela 02: Faixa etária dos respondentes

\begin{tabular}{ccc}
\hline \multicolumn{1}{c}{ Anos } & Frequência & \% \\
\hline 18 a 25 & 6 & $16 \%$ \\
26 a 30 & 8 & $22 \%$ \\
31 a 40 & 9 & $24 \%$ \\
41 a 50 & 12 & $32 \%$ \\
acima de 50 & 2 & $5 \%$ \\
Total & $\mathbf{3 7}$ & $\mathbf{1 0 0 \%}$ \\
\hline
\end{tabular}

Tabela 03: Modalidade de Contratação dos respondentes

\begin{tabular}{cccccc}
\hline & Efetivo & Contratado & Estagiário & Não Responderam & Total \\
\hline Frequência & 24 & 5 & 6 & 2 & 37 \\
$\%$ & $65 \%$ & $14 \%$ & $16 \%$ & $5 \%$ & $100 \%$ \\
\hline
\end{tabular}

Tabela 04: Tempo de experiência dos respondentes

\begin{tabular}{lcc}
\hline \multicolumn{1}{c}{ Ano(s) } & Frequência & $\%$ \\
\hline menos de 1 & 5 & $14 \%$ \\
01 a 05 & 6 & $16 \%$ \\
06 a 10 & 15 & $41 \%$ \\
11 a 20 & 7 & $19 \%$ \\
acima de 20 & 4 & $11 \%$ \\
Total & 37 & $100 \%$ \\
\hline
\end{tabular}

R. Cont. Ufba, Salvador-Ba, v. 8, n. 2, p. 21 - 35, mai-ago 2014 
Quanto à qualificação (tabela 05), 43\% (quarenta e três por cento) possuem pós- graduação em

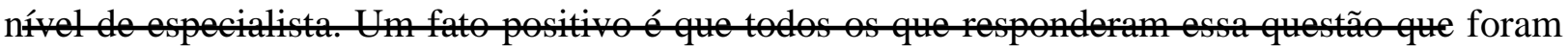
trinta e cinco, e os dois que optaram por deixar em branco, também possuem curso superior, ou seja, os respondentes possuem um nível de conhecimento adequado para a pesquisa. Assim, a área de conhecimento dos mesmos (tabela 06) concentra-se em ciências contábeis; administração, direito e engenharia. Seis servidores deixaram esta questão em branco.

\begin{tabular}{cccccccc}
\multicolumn{7}{c}{ Tabela 05: Respondentes por formação acadêmica } \\
& Ensino Médio & Graduação & Especialista & Mestrado & Doutorado & Não Responderam & Total \\
\hline Frequência & 0 & 15 & 16 & 4 & 0 & 2 & 37 \\
\% & $0 \%$ & $41 \%$ & $43 \%$ & $11 \%$ & $0 \%$ & $5 \%$ & $100 \%$ \\
\hline
\end{tabular}

Tabela 06: Área de formação

\begin{tabular}{lcc}
\hline \multicolumn{1}{c}{ Graduação } & Frequência & \% \\
\hline Contábeis & 9 & $24 \%$ \\
Administração & 9 & $24 \%$ \\
Direito & 6 & $16 \%$ \\
Engenharia & 7 & $19 \%$ \\
Não Responderam & 6 & $16 \%$ \\
\multicolumn{1}{c}{ Total } & $\mathbf{3 7}$ & $\mathbf{1 0 0 \%}$ \\
\hline
\end{tabular}

Conclui-se com a análise da estatística descritiva, que o perfil dos respondentes é adequado para atingir o objetivo desta pesquisa devido a alguns fatores: maioria dos respondentes é do quadro efetivo e com experiência há mais de seis anos, portanto, possuem bastante conhecimento do setor público; e ainda com nível de escolaridade entre graduação e mestrado, em áreas de conhecimento importantes para a implantação das normas.

\subsection{Questões específicas}

Para atingir o objetivo da pesquisa foram elaboradas dez questões específicas quanto à convergência às normas internacionais de contabilidade. Os dados de nove questões específicas foram coletados com a utilização da escala tipo Likert de cinco pontos, com os seguintes significados: (1) Concordo Totalmente; (2) Concordo; (3) Nem concordo, nem discordo; (4) Discordo; (5) Discordo Totalmente. As questões e os resultados constam da tabela 08, elaborada pelo Ranking Médio.

Tabela 08: Ranking Médio da concordância dos respondentes

\begin{tabular}{|c|c|c|c|c|c|c|c|}
\hline Questões & 1 & 2 & $\mathbf{3}$ & 4 & 5 & Total & $\mathbf{R M}$ \\
\hline $\begin{array}{l}\text { 6) A Contabilidade Governamental no Brasil encontra-se em Processo de Convergência } \\
\text { às Normas Internacionais de Contabilidade Aplicadas ao Setor Público }\end{array}$ & 9 & 20 & 7 & 1 & 0 & 37 & 2,00 \\
\hline $\begin{array}{l}\text { 7)Os Servidores Públicos estão sendo capacitados para a aplicação das normas emitidas } \\
\text { pelo Conselho Federal De Contabilidade - CFC }\end{array}$ & 1 & 12 & 13 & 9 & 2 & 37 & 2,97 \\
\hline 8)A Convergência proporcionará uma Gestão Pública mais transparente & 10 & 16 & 9 & 1 & 1 & 37 & 2,11 \\
\hline 9)A Convergência trará uma representação patrimonial mais próxima da realidade & 6 & 21 & 10 & 0 & 0 & 37 & 2,11 \\
\hline $\begin{array}{l}\text { 10)As Normas Brasileiras Aplicadas ao Setor Público - NBCASP, trazem conceitos novos } \\
\text { até então utilizados somente pelo setor privado, em que será adotado o regime contábil } \\
\text { de competência na Contabilidade Patrimonial }\end{array}$ & 3 & 14 & 16 & 3 & 1 & 37 & 2,59 \\
\hline $\begin{array}{l}\text { 11)O Conselho Federal de Contabilidade já emitiu onze normas de contabilidade } \\
\text { aplicadas ao Setor Público que são as NBC T } 16\end{array}$ & 4 & 7 & 18 & 8 & 0 & 37 & 2,81 \\
\hline 12)A Contabilide Governamental deve ter características semelhantes às do Setor Privado & 8 & 11 & 6 & 11 & 1 & 37 & 2,62 \\
\hline $\begin{array}{l}\text { 13)Os Órgãos Públicos estão empenhados em proporcionar treinamento para a } \\
\text { efetiva implantação das normas }\end{array}$ & 2 & 6 & 14 & 10 & 5 & 37 & 3,27 \\
\hline $\begin{array}{l}\text { 14)Servidores Públicos não estão sendo capacitados para a aplicação das normas } \\
\text { emitidas pelo Conselho Federal de Contabilidade - CFC }\end{array}$ & 8 & 11 & 14 & 2 & 2 & 37 & 2,43 \\
\hline $\begin{array}{l}\text { 15)A Convergência às Normas Internacionais Aplicadas ao Setor Público terá } \\
\text { sucesso em sua aplicação }\end{array}$ & 3 & 11 & 17 & 4 & 1 & 36 & 2,69 \\
\hline
\end{tabular}


Analisando a tabela 08 , somente a questão 13, que trata do empenho dos órgãos públicos em proporcionar treinamento para a efetiva implantação das normas houve discordância. Portanto, na amostra analisada, concluiu-se que os respondentes entendem que os órgãos públicos não estão empenhados para o sucesso da convergência (questão 14). A questão 07 sobre a capacitação dos servidores que teve um ranking médio de 2,97 que arredondando é três, mesmo que três seja um ponto neutro, pode-se inferir que os servidores não estão sendo capacitados para aplicação das novas normas, devido as respostas das questões 13 e 14. Pois, se não está havendo empenho dos órgãos públicos em proporcionar treinamento, consequentemente, os servidores não estão sendo capacitados para essa importante mudança na área contábil do setor público. Portanto, as questões 07 e 14 se complementam para validar que os servidores não estão recebendo capacitação para a aplicação das normas, ou que pelo menos que não é suficiente até o momento para a efetiva implantação das mesmas.

Trata-se de um ponto relevante que pode levar ao insucesso da implantação das normas brasileiras aplicadas ao setor público (NBCASP). Desse modo serão apenas uma reforma de 'fachada'.

Há concordância dos respondentes de que a convergência irá trazer benefícios ao setor público, com relatórios mais informativos para tomada de decisão. E ainda o reconhecimento do patrimônio nos balanços públicos trará uma representação econômica mais próxima da realidade (questões 8, 9 e 10).

Para a análise estatística foi utilizado o software SPSS Statistical Package in Social Science, versão 15.0 para Windows e a transferência dos dados atribuiu-se os mesmos valores utilizados no Ranking Médio. Os resultados e outputs da estatística Homals estão expostos a seguir. A tabela 09 traz o resumo do modelo. Os valores próprios (eigenvalues), que segundo Fávero et al (2009, p. 293), mostram a variância total explicada por cada dimensão e variam entre 0 e 1 , quanto mais próximos de 1, maior é a variância explicada por dimensão. As duas dimensões explicam 82,4\% (oitenta e dois vírgula quatro por cento) da variação de dados. Sendo que a dimensão 1 explica $43,3 \%$ (quarenta e três vírgula três por cento) e a segunda

$39,1 \%$ (trinta e nove vírgula um por cento), conforme valores da inércia.

Tabela 09: Resumo do Modelo

\begin{tabular}{lrrrr} 
& & \multicolumn{3}{c}{ Variância explicada por } \\
\hline \multirow{2}{*}{ Dimensão } & Alfa de Cronbach & & Total (Eigenvalue) & Inércia \\
\hline \multicolumn{2}{c}{1} & 0,855 & 4,330 & 0,433 \\
Total & 0,827 & 3,914 & 0,391 \\
Média & & 8,244 & 0,824 \\
\hline \multicolumn{2}{l}{ a. A média de Alfa de Cronbach é baseado na média Eigenvalue }
\end{tabular}

a. A média de Alfa de Cronbach é baseado na média Eigenvalue

Fonte: SPSS

A tabela 10 traz as medidas de discriminação das questões específicas. Segundo Pestana e Gageiro (2008, p. 216) "as medidas de discriminação informam sobre as variáveis que mais contribuem para a definição de cada uma das dimensões". As questões consideradas mais importantes permitem caracterizar cada dimensão. Na primeira dimensão as questões foram: $08,09,10,13$, 14 e 15. Já a segunda dimensão é composta das questões: 07, 08, 11, 12, 13 e 15. As questões 08, 13 e 15 pertencem são expressivas nas duas dimensões. Apesar de entender que todas as questões possuem a sua relevância, a análise estatística apontou aquelas que tratam questões fundamentais dos benefícios e providências que necessitam ser tomadas para a efetiva convergência. A questão 06, em que o objetivo era saber se os respondentes sabiam da convergência, não foi relevante nas duas dimensões. Se o interesse fosse aumentar o valor preditivo, poderia ser excluída da amostra. Esse procedimento é semelhante à análise fatorial, que possibilita a interpretação dos fatores após ser conhecida a contribuição relativa de cada variável (PESTANA E GAGEIRO, 2008). 
Tabela 10: Medidas de Discriminação

\begin{tabular}{llll}
\hline & \multicolumn{4}{c}{ Dimensão } \\
\hline & 1 & \multicolumn{2}{c}{ 2 Média } \\
Q_06 & 0,339 & 0,381 & 0,360 \\
Q_07 & 0,253 & $\mathbf{0 , 5 9 1}$ & 0,422 \\
Q_08 & $\mathbf{0 , 4 7 3}$ & $\mathbf{0 , 4 1 2}$ & 0,443 \\
Q_09 & $\mathbf{0 , 4 9 3}$ & 0,035 & 0,264 \\
Q_10 & $\mathbf{0 , 5 1 7}$ & 0,231 & 0,374 \\
Q_11 & 0,404 & $\mathbf{0 , 4 0 1}$ & 0,403 \\
Q_12 & 0,283 & $\mathbf{0 , 4 9 9}$ & 0,391 \\
Q_13 & $\mathbf{0 , 5 8 2}$ & $\mathbf{0 , 5 4 8}$ & 0,565 \\
Q_14 & $\mathbf{0 , 4 8 9}$ & 0,196 & 0,342 \\
Q_15 & $\mathbf{0 , 4 9 7}$ & $\mathbf{0 , 6 2 0}$ & 0,558 \\
\hline
\end{tabular}

Fonte: SPSS

A figura 02 corrobora com a análise da tabela 10 quanto as variáveis que mais importantes nas duas dimensões.

Figura 02: Gráfico de Medidas de Discriminação das questões específicas

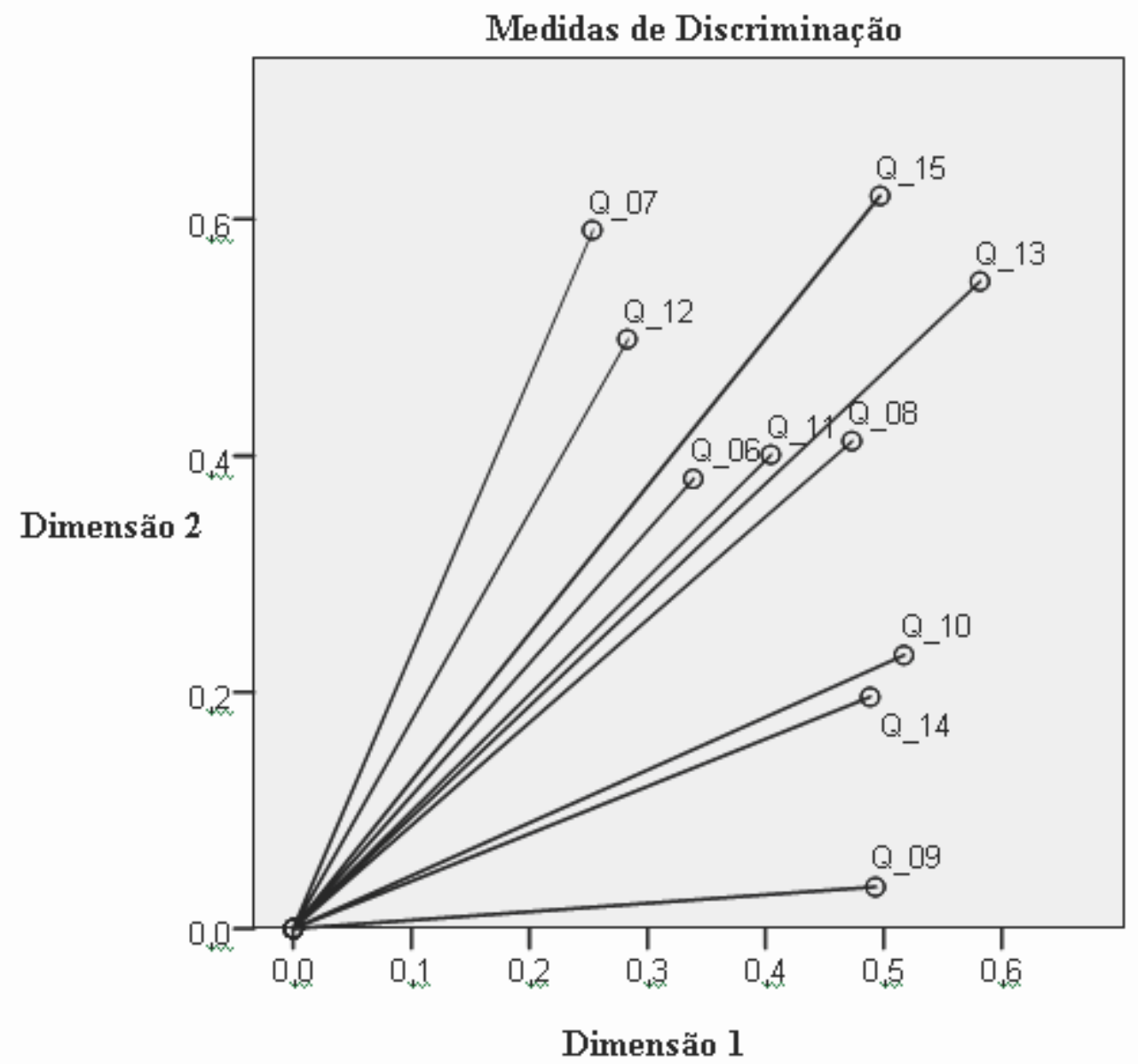

Fonte: SPSS

Foi incluída uma última questão em que o respondente poderia escolher mais de uma opção. A questão foi: "Assinale o(s) termo(s) que conhece que está(ão) sendo introduzido(s) com a 
convergência: valor justo; impairment, provisão, resultado econômico, essência sobre a forma, vida útil, competência, custo de oportunidade, ou não conheço nenhum dos termos".

Quatro respondentes, aproximadamente $11 \%$ (onze por cento) não conheciam nenhum dos termos. A tabela 11 traz o resultado final da questão.

Tabela 11: 'Novos' termos introduzidos com a convergência

\begin{tabular}{lrc}
\hline \multicolumn{1}{c}{ Termo } & Quantidade & \% \\
\hline Valor Justo & 30 & $81,08 \%$ \\
Impairment & 21 & $56,76 \%$ \\
Provisão & 24 & $64,86 \%$ \\
Resultado Econômico & 25 & $67,57 \%$ \\
Essência sobre a Forma & 22 & $59,46 \%$ \\
Vida Útil & 23 & $62,16 \%$ \\
Competência & 26 & $70,27 \%$ \\
Custo de Oportunidade & 25 & $67,57 \%$ \\
Não conheço & 4 & $10,81 \%$ \\
\hline
\end{tabular}

Analisando a tabela 11, percebe-se que, na média, os respondentes possuem um grau de conhecimento do que será introduzido com a convergência. O termo mais conhecido foi "valor justo". Esse termo é importante, pois é uma mudança de paradigma no reconhecimento de certos ativos e passivos, tanto no setor público quanto privado. Entretanto, um ponto que merece destaque e precisa ser corrigido, pela amostra analisada, não está havendo empenho pelos órgãos públicos para a capacitação dos servidores para a efetiva implantação das normas internacionais. Se não houver empenho, principalmente nos municípios, os resultados esperados com a convergência não serão alcançados. Se operacionalmente a convergência for implantada com sucesso, gerando informações úteis para os seus usuários, não se pode concluir que obteve sucesso. Se essas informações geradas com base no regime de competência não forem utilizadas pelos gestores públicos para a tomada de decisão econômica não serão úteis, ou seja, não irão agregar valor. E a responsabilidade de agregar valor, proporcionando o desenvolvimento econômico é do gestor público de todas as esferas do governo. Assim não irão gerar benefícios econômicos futuros que é o principal objetivo da informação contábil.

É importante ressaltar que esse fato está acontecendo em alguns países que adotaram o regime de competência nos últimos anos. Wynne (2012) argumenta que existem evidências de que a informação adicional gerada pelo regime de competência é raramente utilizada para gerenciar as entidades do setor público com mais eficiência. E ainda que os benefícios esperados com a reforma não estão sendo alcançados na prática, nos poucos países que adotaram o regime de competência até o momento.

Outro aspecto relevante é a redução da assimetria informacional entre o Estado e a sociedade, pois com maior transparência, os cidadãos poderão cobrar dos gestores públicos a aplicação eficiente dos recursos públicos.

Não é suficiente os servidores estarem familiarizados com os conceitos novos, eles precisam aplicá-los na prática e sem capacitação isso não será possível.

Os resultados encontrados nesta pesquisa vêm ao encontro do pensamento de alguns autores citados no referencial teórico.

\section{CONSIDERAÇÕES FINAIS}

O objetivo deste artigo foi analisar a percepção dos servidores públicos quanto à convergência Normas Brasileiras Aplicadas ao Setor Público, no município de Uberlândia. A hipótese levantada 
no início desse artigo foi confirmada, os servidores públicos do município de Uberlândia, ainda estão desatualizados para a efetiva convergência contábil aplicada no setor público.

Diante do exposto, pode-se inferir que os servidores estão cientes da importância da convergência, possuem um nível básico de conhecimento sobre o tema, entretanto, não está havendo empenho pelos órgãos públicos do município de Uberlândia para a capacitação dos mesmos para a efetiva implantação das normas internacionais.

Ressalta-se que esse resultado não pode ser generalizado, por tratar-se de um estudo de caso.

A análise descritiva traçou o perfil dos respondentes, demonstrando que a amostra foi adequada para atingir o objetivo desta pesquisa. A análise do Ranking Médio contribuiu para a análise das questões específicas evidenciando o nível de conhecimento dos servidores públicos de Uberlândia quanto à convergência às normas internacionais aplicadas ao setor público. Os servidores possuem um bom nível de conhecimento teórico, mas não estão sendo capacitados para aplicar os conceitos na prática. E por último o uso da estatística homals teve por objetivo ressaltar as principais questões em debate sobre a convergência. É importante ressaltar que essa técnica também é exploratória não podendo ser generalizada.

Outros estudos podem ser realizados em outros municípios e comparar os resultados. É preciso traçar uma visão geral da convergência para averiguar se está tendo empenho ou não dos entes da federação para a efetiva implantação das normas internacionais aplicadas ao setor público. Vale destacar que esse empenho envolve também recursos e sistemas de informações adequados.

\section{REFERÊNCIAS}

ANDRADE, Maria Elisabeth Moreira Carvalho; CARVALHO, Luiz Nelson Guedes de. Análise da adoção do regime de competência no setor público internacional. Revista FSA. Teresina, v. 10, n. 1, p. 40-58, jan./mar. 2013. Disponível em: <http://dx.doi.org/10.12819/2013.10.1.3> Acesso em: 29 set. 2014.

AZEVEDO, R. R. de, et. al. (org). Normas Brasileiras de Contabilidade Aplicadas ao Setor Público. Nova Letra, 2009.

BRASIL. Lei no 4.320, de 04 de março de 1964. Estatui Normas Gerais de Direito Financeiro para elaboração e controle dos orçamentos e balanços da União, dos Estados, dos Municípios e do Distrito Federal. Diário Oficial [da] República Federativa do Brasil, Poder Legislativo, Brasília, DF, 23 mar. 1964, Seção 1, p. 2745. Retificação Diário Oficial [da] República Federativa do Brasil, Poder Legislativo, Brasília, DF, 9 abr. 1964, p. 3195.

Lei Complementar $n^{\circ} 101$, de 4 de maio de 2000. Estabelece normas de finanças públicas voltadas para a responsabilidade na gestão fiscal e dá outras providências. Diário Oficial [da] República Federativa do Brasil, Poder Legislativo, Brasília, DF, 5 mai. 2000, Seção 1, p. 1.

Portaria $\mathrm{n}^{\circ} 184$, de 25 de agosto de 2008. Estabelece normas de finanças públicas voltadas para a responsabilidade na gestão fiscal e dá outras providências. Disponível em: <http://www.fazenda.gov.br/portugues/legislacao/portarias/2008/portaria184.asp > Acesso o em: 20 jul. 2012.

Portaria $n^{\circ} 828$, de 14 de dezembro de 2011.

Altera o prazo de implementação do Plano de Contas Aplicado ao Setor Público e dá outras providências. Disponível em:

http://www.tesouro.fazenda.gov.br/legislacao/download/contabilidade/PortSTN_828_201112 14.pdf. Acesso o em: 20 jul. 2012.

R. Cont. Ufba, Salvador-Ba, v. 8, n. 2, p. 21 - 35, mai-ago 2014 
Portaria $n^{\circ} 231$, de 29 de maço 2012. Altera o prazo de divulgação do cronograma de ações para adequação aos procedimentos contábeis apresentados na Portaria STN $\mathbf{n}^{\circ}$ 828/2011 e dá outras providências. Disponível em:

<http://www.tesouro.fazenda.gov.br/legislacao/download/contabilidade/Portaria_STN_231_2 012.pdf> Acesso o em: 20 jul. 2012.

. STN - Secretaria do Tesouro Nacional. Análise da Aplicabilidade das Normas Internacionais de Contabilidade Aplicadas ao Setor Público. Disponível em: <http://www.stn.fazenda.gov.br/contabilidade_governamental/download/5_IPSAS_Converge

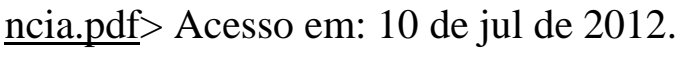

BRESSER PEREIRA, L. C. A Reforma da Administração Pública. Capítulo 16. Crise Econômica e Reforma do Estado no Brasil. São Paulo, Editora 34, 269-294, 1996.Disponível em:〈http://www.bresserpereira.org.br/papers/1996/96.ReformaDaAdministracaoPublica.pdf > Acesso em: 01 de abril de 2012.

; SPINK, Peter (orgs.). Gestão do Setor Público: estratégia e estrutura para um novo Estado. Reforma do Estado e Administração Pública Gerencial. Rio de Janeiro. Editora Fundação Getúlio Vargas: 21-38. 1998. Disponível em: http://www.bresserpereira.org.br/papers/1998/98-GestaoDoSetorPublico-

Estrategia\&Estrutura.pdf. Acesso em: 01 de abril de 2012.

CONSELHO FEDERAL DE CONTABILIDADE - CFC. Resolução CFC n ${ }^{\circ} 1.128$, de 21 de novembro de 2008. Aprova a NBC T 16.1 - Conceituação, Objeto e Campo de Aplicação. Disponível em: <http://www.cfc.org.br >. Acesso em: 24 jun. 2011.

DARÓS, L. L.; PEREIRA, A. S. Análise das Normas Brasileiras de Contabilidade aplicadas ao setor público - NBCASP: mudanças e desafios para a contabilidade pública. In: $9^{\mathrm{O}}$ Congresso USP de Controladoria e Contabilidade. 2009. Disponível em <http://www.congressousp.fipecafi.org/artigos92009/467.pdf >. Acesso em 20 jul 2012.

ELLWOOD, S; NEWBERRY, S. Public Sector Accrual Accounting: Instituting Neoliberal Principles? Accounting, Auditing \& Accountability Journal, Vol. 20 No 4, 2007.

ERNEST \& YOUNG. (2010). Toward transparency: a comparative study of governmental accounting in Europe. [S.1.]: Ernest \&Young.

FÁVERO, L. P.; BELFIORE, P.; SILVA, F. L.; CHAN, B. L. Análise de dados: modelagem multivariada para tomada de decisões. Ed. Campus Elsevier, 2009.

IFAC International Federation of Accountants. Disponível em: 〈http://www.ifac.org> Acesso em: 2 abr. 2012.

IUDÍCIBUS, Sérgio de. Teoria da contabilidade. $7^{\text {a }}$ ed. São Paulo: Atlas, 2004.

JÄRVINEN, J. Shifting NPM agendas and management accountants' occupational identities. Accounting, Auditing \& Accountability Journal. Vol. 22 No. 8, 2009., pp. 1187-1210

KHAIR, Amir Antônio. Lei de responsabilidade fiscal: guia de orientação para as prefeituras. Brasília. Ministério do Planejamento e Gestão. BNDES. 2000. 
LIMA, D.V.; CASTRO, R. G. Contabilidade Pública: Integrando União, Estados e Municípios (Siafi e Siafem). SãoPaulo: Atlas, 2003.

LIMA, D.V.; SANTANA, C. M.; GUEDES, M. A. As Normas Brasileiras de Contabilidade aplicadas ao setor público e a legislação contábil pública brasileira: uma análise comparativa à luz da teoria contábil. Revista de Contabilidade, Gestão e Governança. v. 12, n. 2, p. 15 23, mai/ago 2009.

MATIAS-PEREIRA, J. . Administração Pública Comparada: Uma Avaliação das Reformas Administrativas do Brasil, EUA e União Européia - RAP. Revista Brasileira de

Administração Pública, v. 42, p. 61-82, 2008. Disponível em:

http://www.scielo.br/pdf/rap/v42n1/a04v42n1.pdf. Acesso em: 30 ago. 2009

MORAIS, Leandro Morais de; PLATT NETO, Orion Augusto. A Reforma Contábil Promovida pelas NBCASP e o Processo de Convergência: Implicações e Perspectivas. RIC Revista de Informação Contábil, Vol. 6, no 2, p. 01-20, Abr-Jun/2012.

NIYAMA, Jorge Katsumi; SILVA, Cesar Augusto Tibúrcio. Teoria da contabilidade. São Paulo: Atlas, 2008.

OLIVEIRA, Luciel Henrique de. Exemplo de cáclulo de Ranking Médio para Likert. Notas de Aula. Metodologia Científica e Técnicas de Pesquisa em Administração. Mestrado em Adm. e Desenvolvimento Organizacional. PPGA CNEC/FACECA: Varginha, 2005.

PÉREZ, C. C.; LÓPEZ-HERNANDEZ, A. M. Governmental financial transparency in MERCOSUR member countries. International Review of Administrative Sciences. V 75(1), 169-181.

PESTANA, M. H.; GAGEIRO, J. N. Análise de dados para ciências sociais: a complementaridade do SPSS. 5. ed. Lisboa: Silabo, 2008.

PIGATTO, J. A. M.; HOLANDA, V. B.; MOREIRA, C. R.; CARVALHO, F. A. A importância da contabilidade de competência para a informação de custos governamental. Revista de Administração Pública - RAP. Rio de Janeiro 44(4):821-37, jul./ago. 2010

PISCITELLI, R.B. TIMBÓ, M.Z.F. ROSA, M.B. Contabilidade Pública: uma abordagem da administração financeira pública. 9 ed. São Paulo: Atlas, 2006.

PLATT NETO, O. A.; CRUZ, F. DA; ENSSLIN, S.R.; ENSSLIN, L. Publicidade e Transparência das Contas Públicas: obrigatoriedade e abrangência desses princípios na administração pública brasileira. Contabilidade Vista e Revista, v. 18, n. 1, p. 75-94, jan./ mar. 2007.

REIS, H. D. Regime de caixa ou competência: eis a questão. Revista de Administração Municipal, v. 52, n.260, p. 37-48, 2006.

REVOREDO, Márcia Maria Oliveira. Brasil rumo aos padries internacionais de contabilidade para o setor público: uma análise sob a ótica do Financial Management Reform Process Model de Lüder. 2008. 170f. Dissertação (Mestrado em Ciências 
Contábeis) - Faculdade de Administração e Finanças, Universidade do Estado do Rio de Janeiro, Rio de Janeiro, 2008.

RIBEIRO FILHO, J. F.; LOPES, Jorge Expedito de Gusmão; SILVA, Lino Martins da; PEDERNEIRAS, Marcleide Maria Macedo. True and Fair View e Accountability na gestão pública: uma análise das percepções de auditores de Tribunais de Contas Estaduais. In: IAAER - ANPCONT (3rd) International Accounting Congress - Accounting Internationalization: Currents and future trends., 2009, São Paulo - Brasil. Congresso ANPCONT 2009. Blumenau - SC : ANPCONT FURB, 2009. v. 1. p. 1-15.

ROSA, Maria Berenice. Contabilidade do Setor Público. São Paulo: Atlas, 2011.

SANTANA JUNIOR, Jorge José Barros de. Transparência Eletrônica: uma análise dos níveis de transparência apresentados nos sites dos Poderes e Órgãos dos Estados e Distrito Federal do Brasil. Recife-PE, 2008. Dissertação - Programa Multinstitucional e Interregional de Pós-Graduação em Ciências Contábeis da Universidade de Brasília, da Universidade Federal de Pernambuco, da Universidade Federal da Paraíba e da Universidade Federal do Rio Grande do Norte. Recife, 2008.

SÖTHE, Ari; SCARPIN, Jorge Eduardo. Estudo n 14 do IFAC: impactos na implementação do regime de competência no governo municipal de Iporã do Oeste $-\mathrm{SC}$. In: $10^{\mathrm{O}}$ Congresso USP de Controladoria e Contabilidade. 2010. Disponível em <http://www.congressousp. fipecafi.org/artigos102010/290.pdf> Acesso em 20 jul 2012.

VERGARA, Sylvia Constant. Projetos e Relatórios de Pesquisa em Administração. 2ed. São Paulo: Atlas, 1998.

WYNNE, Andy. Is The Move To Accrual Based Accounting A Real Priority For Public Sector Accounting? Fund Public Digest. The International consortium on Governmental Financial Management. v. 07, n. 1, p. 25-38, 2007.

. An Efficient Technical Solution or an Ideologically Contested Approach the balance sheet for business style accrual accounting in the public sector. International Journal on Governmental Financial Management. Vol. 12, 1, 2012.

ZARTH, S. B.; A Aplicação Integral do Regime de Competência na Contabilidade Pública Brasileira Segundo as Normas Brasileiras de Contabilidade Aplicadas ao Setor Público. Revista de Negócios, n. 9, março de 2010. 